\title{
Validation of Academic burnout scale among Moroccan trainee teachers
}

\author{
Zineb BOUMAAIZE ${ }^{1,2}$, Youssef EL MADHI , Hajar DARIF ${ }^{4}$, Abdelmajid SOULAYMANI4, \\ Anne-Marie VONTHRON ${ }^{5}$, Bouazza EL WAHBI ${ }^{6}$, Hanan EL FAYLALI ${ }^{2}$.
}

\author{
${ }^{1}$ Research Laboratory Innovation \& Information System, EuRSED Vienne France. \\ ${ }^{2}$ Research Laboratory of Informatics Systems and Optimization, Faculty of science, Ibn Tofail, \\ University, Kénitra, Morocco. \\ ${ }^{3}$ Research Laboratory: Education, Environment \& Health (EES) at CRMEF Rabat / Salé / Kénitra. \\ ${ }^{4}$ Laboratory of Genetics and Biometrics, Faculty of science, Ibn Tofail University, Kénitra, Morocco \\ ${ }^{5}$ Department of Psychology, University Paris Nanterre, 92000 Nanterre, France. \\ ${ }^{6}$ Laboratory of Analysis, Geometry and Applications, Faculty of science, Ibn Tofail University, \\ Morocco.
}

Corresponding Author: zineb.boumaaize@uit.ac.ma

\begin{abstract}
With the aim of measuring trainee's academic burnout, the Maslach Burnout Inventory -Student Scale was translated, revised and validated. A cross-sectorial study took place between November and March 2020.The sample consisted 160 trainee teachers $(36 \%$ males, 64\% females) from Kénitra Regional Center of Education and Training (CRMEF). The average age is $27.94 \pm 5.44$ years. The Data collected was analyzed by SPSS to establish descriptive analysis, calculate reliability, and other psychometric properties. An exploratory factor analysis was used to validate the MBI-SS instrument. The results indicated the conservation of three factors. All subscales had satisfactory reliability. This study can be applied to more specific samples in other regional centers.
\end{abstract}

Keywords: Trainee teacher, academic burnout, validation, reliability.

\section{Introduction}

In recent years, the number of academic burnout studies has increased and gotten a lot of on attention. Despite, the number of studies focused to academic burnout in North Africa, especially on Morocco, still relatively limited.

Academic burnout were described as emotional exhaustion, a tendency to depersonalization, and a feeling of low personal accomplishment displayed in the learning process due to course load, course stress or other psychological factors [1] Academic Burnout is a problemaffecting student. They feel exhaustion related to demands studies, cynical attitudes and ineptness feelings into studies [2] Beck [3] defines the academic burnout as a psychological syndrome, which includes physical, emotional and psychological depletion [4].It is characterized by three dimensions : academic exhaustion due to study demands, academic disinterest towards study and academic inefficiency as a student.[5] 
Academic Burnout triggered by a chronic academic stress can be caused through course load, inadequate social support, ineffective peer interactions[6], personality traits, family and financial concerns. Thus, academic burnout was manifested by high emotional exhaustion, high cynism and low academic inefficiency. Like all psychosomatic disorders, academic burnout leads to serious physical and mental problems such as anxiety, depression and frustration [7].In the organizational side, academic burnout may reduce student involvement, academic performance and increased student dropout rate. [5]

For these reasons, it is necessary to develop a valid and a specific Moroccan instrument in order to examine academic burnout into Moroccan trainee teachers and prevent this syndrome at the beginning of their careers. The aim of this study is to evaluate the psychometric validity of Arabic version of MBI-SS dedicated to Moroccan trainee teachers.

\section{Material and Method}

\section{Participants}

This cross-sectional study took place between November and March 2020. The MBI-SS survey was self-administrated to assess the academic burnout into trainee teachers during training period. The participants were informed about the aim of the study. Participants in this survey were 184 trainee teachers from Regional center of Education and Training in Morocco (KENITRA annex). From these trainees, 24 did not answer to the complete survey and were eliminated from the study. 160 trainee teachers (36\% male, 64\% female) met the eligibility criteria of our study.

\section{Measures: Maslach Burnout Inventory- Student Scale}

To assess academic burnout, Maslach Burnout Inventory-Student Scale was used for this purpose.[8] It is the most commonly scale designed to measure the burnout level related to studies. The constructs contains 15 items that represent three subscales: emotional exhaustion (5 items), cynism (4 items) and academic efficacy (6 items). All items have been adapted to the study field. Some vocabulary has been replaced such as (university day-training day) (student- trainee teacher). Trainees were asked to indicate the level of agreement with every item, which were scored with 7-point frequency rating scale ranging from 0 (never) to 6 (always). High scores on emotional exhaustion (EE), cynism (CY) and low scores on academic efficacy (AE) are predictive of academic burnout (the academic efficacy scores are reversed).[9]

\section{Questionnaire Translation}

An Arabic translation of MBI-SS were established to provide a validated version destined to Moroccan trainee teachers (Arabspeaking population). The Vallerand transcultural method suggested by previous studies have been followed. Four bilingual professors working on collaboration in the same field were devised on two groups. Each of them translated independently in order to have a good quality translation. The group who have no information on the underlying objectives of the study back translates the target language versions into the source language. Based on the consensus of the two committees, the final version were developed and revised following suggestions obtained from a pilot group of 30 trainee teachers.

\section{Statistical methodology}

In this study, the MBI-SS validation process was based on two steps. First, the reliability of the scale and three dimensions was calculated through the Cronbach's $\alpha$ coefficient. In order to extract the variables and measure the dimensionality of the instrument, the collected data was then subjected to an Exploratory Factor Analysis (EFA). The factor structure was studied by conducting a principal axis factor (PAF) and oblimin rotation. All data were analyzed by using the Statistical Package for the Social Sciences (SPSS) statistical software.

The Kaiser - Meyer - Olkin (KMO) measurement was used to examine the sampling adequacy. The KMO score should preferably be higher than 0.60. For a feasible factor analysis, Bartlett's sphericity test was calculated. It must be significant $(\mathrm{p}<0.05)$. 
The internal coherence of all MBI-SS items and sub-scales maintained after oblimin rotation were examined using the Cronbach $\alpha$.

\section{Results}

\section{Socio-demographic and professional data}

The questionnaire was completed by 160 trainee teacher affiliated to Regional Center of Education and Training (CRMEF). Men represented $36 \%$, while $64 \%$ of participants are women. The average age is $27.94 \pm 5.44$ years. More than two thirds $(72.1 \%)$ of participants were single. $26.5 \%$ are married.

$29.4 \%$ of the trainees have professional experience in teaching, while $70.6 \%$ of them had not worked before entering the training. (Table 1)

Table 1: Socio-demographic characteristics

\begin{tabular}{|c|c|}
\hline Characteristics & $\mathbf{n}$ (\%) \\
\hline Gender & \\
\hline Male & $58(36)$ \\
\hline Female & $102(64)$ \\
\hline Age & \\
\hline$[21-25[$ & $51(32,1)$ \\
\hline$[25-30[$ & $70(43,8)$ \\
\hline$[30-35[$ & $21(13,3)$ \\
\hline$[35-40[$ & $18(10,8)$ \\
\hline Marital status & \\
\hline Single & $115(72,1)$ \\
\hline Married & $42(26,5)$ \\
\hline Divorced & $3(1,4)$ \\
\hline Academic degree & \\
\hline Licence & $110(68,4)$ \\
\hline Master's & $46(29,1)$ \\
\hline Phd & $4(2,5)$ \\
\hline \multicolumn{2}{|l}{} \\
\hline & \\
\hline & \\
\hline & \\
\hline & \\
\hline & \\
\hline & \\
\hline & \\
\hline &
\end{tabular}

\section{Questionnaire validity}

To conduct exploratory factorial analysis, we chose Principal axis Factor (PAF). The KaiserMeyer-Olkin (KMO) and Bartlett's sphericity tests are used. The results show that the KMO presented was $0,841>0.5$. The Bartlett's Test of sphericity is significant $(\mathrm{sig}<0.001)$.

Factor structure of MBI-SS defined three factors: factor I was named "emotional exhaustion" and showed an eigenvalue of 5.329, which explained the $35 \%$ total variance; factor II, named "cynicism", reached an eigenvalue of 2.439 , accounting for the $14 \%$ total variance; and factor III, named "academic efficacy", had an eigenvalue of 1.103 , thus explaining the $4.9 \%$ total variance. Table 1 represent the factor solution obtained. (Table 2)

Table 2: MBI-SS Factor Matrix after Rotation

\begin{tabular}{|l|c|l|l|}
\hline \multirow{2}{*}{} & \multicolumn{3}{|c|}{ Component } \\
\cline { 2 - 4 } & AE & \multicolumn{1}{|c|}{ CY } & EE \\
\hline AE_1 &, 856 & & \\
\hline AE_2 &, 837 & & \\
\hline AE_3 &, 790 & & \\
\hline AE_4 &, 680 & & \\
\hline AE_5 &, 553 & &, 870 \\
\hline AE_6 &, 475 & &, 708 \\
\hline CY_1 & &, 765 &, 664 \\
\hline CY_2 & &, 699 &, 453 \\
\hline CY_3 & &, 631 &, 382 \\
\hline EE_1 & & & 0,82 \\
\hline EE_2 & & & 4,900 \\
\hline EE_3 & & & \\
\hline EE_4 & & & \\
\hline EE_5 & & & \\
\hline $\begin{array}{l}\text { Cronbach's } \\
\text { alpha }\end{array}$ & $0,88,941$ & \\
\hline $\begin{array}{l}\text { \% variance } \\
\text { explained }\end{array}$ & 35,006 & 14,015 & \\
\hline $\begin{array}{l}\text { \% total variance } \\
\text { explained }\end{array}$ & & & \\
\hline $\begin{array}{l}\text { measurement } \\
\text { of Kaiser-Meyer- } \\
\text { Olkin sampling } \\
\text { (KMO) }\end{array}$ & & & \\
\hline
\end{tabular}




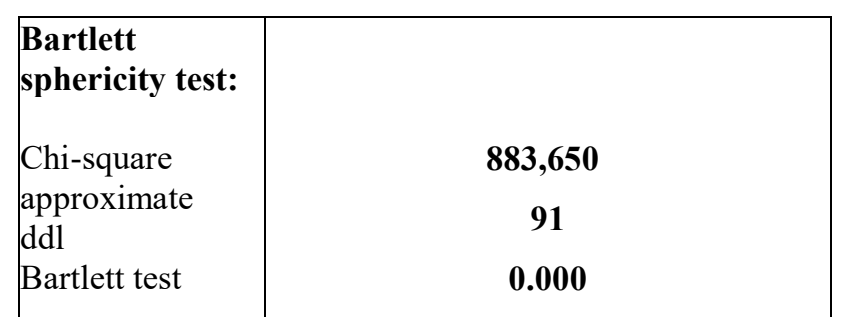

\section{Discussion}

Researchers currently focus on the academic burnout issue. The aim of this study is to examine the multidimensional structure of MBI-SS (Arabic version) in order to diagnose, prevent the prevalence and development of academic burnout into trainee teachers during training and after their assignment. Subsequently, an exploratory factor analysis was performed to reduce the dimensions and validate the construct. the threedimensional aspect was retained for the first factor emotional exhaustion (EE) due to training requirements, the second factor cynicism (CY) referring to an attitude detached from training and the third factor academic efficacy (AE) related to the feeling of accomplishment as a trainee teacher. The three- dimensional structure has been claimed to be factorial valid for students in several countries[10] [11] [12]. In Serbia, a study conducted by 760 Serbian physicians student [13] determined that principal component analysis with Oblimin rotation indicated three principal components that explain a variance of $64.9 \%$. Similarly in France, the three-dimensional model of the MBI-SS structure was confirmed in study carried out by 667 French students [9]. Shin et al. (2011)[14] reported reliability estimates for the MBI-SS as .86 for exhaustion, .82 for cynicism, and .82 for academic inefficacy. Therefore, the MBI-SS reliability tested by Cronbach's $\alpha$ exceed 0.7. [15]

Ilic[13] reported that Cronbach's $\alpha$ of MBI-SS was 0.757 , while Cronbach's $\alpha$ coefficients for the three dimensions Exhaustion, Cynicism and Academic Efficiency were $0.869,0.856$ and 0.852. Yavuz and Dogan [16] showed that $\alpha$ Cronbach's sub-scales emotional exhaustion, cynicism and academic efficiency were 0.838 , 0.844 and 0.875 , while Tsubakita and Shimazaki [17] revealed that the coefficients $\alpha$ are $0.76,0.85$ and 0.78 respectively. Based on these results, we can affirm that MBI-SS retained the three-dimensional structure of the original version.

\section{Conclusion}

For the purpose of protecting novice teachers mental well-being and avoid losing interest during training period, the MBI-SS instrument was proposed to Moroccan trainee teachers. It may contribute to measure this syndrome and prevent developing in subsequent training stages until professional integration.

\section{Implications and recommendations}

If trainee teachers are already exposed to academic burnout in the form of emotional exhaustion and cynism sense (detachment to study), then how they can escape to its professional impact especially in their development career and their interactions with students?

Academic burnout might lead to higher rates of absenteeism, chronic fatigue, decreased concentration, affects mental health and trainee well-being. A based perspectives related to this topic could enhance trainees knowledge to develop the coping manners. It is important that students have a toolbox of strategies in place to deal with this syndrome and prevented its progression. Further, developing a strong colleague relationships, high self-efficacy sense and management professional skills.

\section{Study limitations}

This study were addressed on trainees whom continue their training in Rabat-Salé-Kénitra regional center. For that, there is a need to conduct studies in other regions and compare the results obtained for each representative sample. However, a sample size could be limitation criteria.

\section{Acknowledgements:}

This study was carried out within the framework of the APPRENDRE Program /project no. 95 funded by the Agence Universitaire de la Francophonie (AUF).

The authors thank the trainee teachers engaged 
in this work. Our thanks to everyone who has contributed directly or indirectly to the success of this research.

\section{References}

[1] H.-J. Yang, 'Factors affecting student burnout and academic achievement in multiple enrollment programs in Taiwan's technical-vocational colleges', International Journal of Educational Development, vol. 24, no. 3, pp. 283-301, May 2004, doi: 10.1016/j.ijedudev.2003.12.001.

[2] W. B. Schaufeli, I. M. Martínez, A. M. Pinto, M. Salanova, and A. B. Bakker, 'Burnout and Engagement in University Students: A Cross-National Study', Journal of Cross-Cultural Psychology, vol. 33, no. 5, pp. 464-481, Sep. 2002, doi: 10.1177/0022022102033005003.

[3] Y. Babenko-Mould and H. K. S. Laschinger, 'Effects of Incivility in Clinical Practice Settings on Nursing Student Burnout', International Journal of Nursing Education Scholarship, vol. 11, no. 1, pp. 145-154, Jan. 2014, doi: 10.1515/ijnes-2014-0023.

[4] J. H. Yu, S. J. Chae, and K. H. Chang, 'The relationship among self-efficacy, perfectionism and academic burnout in medical school students', Korean J Med Educ, vol. 28, no. 1, pp. 49-55, Jan. 2016, doi: 10.3946/kjme.2016.9.

[5] O. Koropets, A. Fedorova, and I. Kacane, 'EMOTIONAL AND ACADEMIC BURNOUT OF STUDENTS COMBINING EDUCATION AND WORK', Palma, Spain, Jul. 2019, pp. 8227-8232, doi: 10.21125/edulearn.2019.2038.

[6] S.-S. Shih, 'An Examination of Academic Coping Among Taiwanese Adolescents', The Journal of Educational Research, vol. 108, no. 3, pp. 175-185, May 2015, doi: 10.1080/00220671.2013.867473.

[7] S. J. Lee, Y. J. Choi, and H. Chae, 'The effects of personality traits on academic burnout in Korean medical students', Integrative Medicine Research, vol. 6, no. 2, pp. 207-213, Jun. 2017, doi: 10.1016/j.imr.2017.03.005.

[8] C. Faye-Dumanget, J. Carré, M. Le Borgne, and Pr. A. H. Boudoukha, 'French validation of the Maslach Burnout Inventory-Student Survey (MBI-SS)', $J$ Eval Clin Pract, vol. 23, no. 6, pp. 12471251, Dec. 2017, doi: 10.1111/jep.12771.

[9] C. Faye-Dumanget, J. Belleil, M. Blanche, M. Marjolet, and A.-H. Boudoukha, 'L'épuisement académique chez les étudiants : effet des variables sociodémographiques sur les niveaux de burn-out', Annales Médicopsychologiques, revue psychiatrique, vol. 176, no. 9, pp. 870-874, Nov. 2018, doi: 10.1016/j.amp.2017.09.012.

[10]Z. Rostami, M. R. Abedi, W. B. Schaufeli, S. A. Ahmadi, and A. H. Sadeghi, 'The Psychometric Characteristics of Maslach Burnout Inventory Student Survey: Among Students of Isfahan University', p. 4.

[11]M. S. Carlotto and S. G. Câmara, 'Características psicométricas do Maslach Burnout Inventory - Student Survey (MBI-SS) em estudantes universitários brasileiros', vol. 11, no. 2, p. 8, 2006.

[12]Q. Hu and W. B. Schaufeli, 'The Factorial Validity of the Maslach Burnout Inventory-Student Survey in China', Psychol Rep, vol. 105, no. 2, pp. 394-408, Oct. 2009, doi: 10.2466/PR0.105.2.394408.

[13]M. Ilic, Z. Todorovic, M. Jovanovic, and I. Ilic, 'Burnout Syndrome Among Medical Students at One University in Serbia: Validity and Reliability of the Maslach Burnout Inventory—Student Survey', Behavioral Medicine, vol. 43, no. 4, pp. 323-328, Oct. 2017, doi: 10.1080/08964289.2016.1170662.

[14]H. Shin, A. Puig, J. Lee, J. H. Lee, and S. M. Lee, 'Cultural validation of the Maslach Burnout Inventory for Korean students', Asia Pacific Educ. Rev., vol. 12, no. 4, pp. 633-639, Dec. 2011, doi: 10.1007/s12564-011-9164-y.

[15]L. J. Cronbach, 'Coefficient alpha and the internal structure of tests', Psychometrika, vol. 16, no. 3, pp. 297-334, Sep. 1951, doi: 10.1007/BF02310555.

[16]G. Yavuz and N. Dogan, 'Maslach Burnout Inventory-Student Survey (MBISS): A Validity Study', Procedia - Social and Behavioral Sciences, vol. 116, pp. 2453-2457, Feb. 2014, doi: 10.1016/j.sbspro.2014.01.590. 
[17]T. Tsubakita and K. Shimazaki, 'Constructing the Japanese version of the Maslach Burnout Inventory-Student Survey: Confirmatory factor analysis: MBI-SS in Japan', Japan Journal of Nursing Science, vol. 13, no. 1, pp. 183188, Jan. 2016, doi: 10.1111/jjns. 12082. 